\section{Papel da Vitamina D na Função Neuro-Muscular}

\section{RESUMO}

A vitamina $D$, através de suas ações no intestino, rim, osso e glândulas paratiróides, é um hormônio fundamental para a homeostase do cálcio e para o desenvolvimento de um esqueleto saudável. Além disso, receptores deste hormônio podem ser encontra dos em quase todos os tecidos do organismo e outras a ções não rela ciona das ao meta bolismo mineral têm sido imputa das a ele. Na célula muscular esquelética, a vitamina D atua através do mecanismo clássico de ligação a um receptor nucleare também atra vés da ligação a um receptor de membrana, realizando ações que envolvem o transporte de cálc io, a síntese protéica e a velocidade de contração muscular. Clinicamente, a deficiência de vitamina $D$, que é bastante comum em idosos, inclusive em nosso país, tem sido relacionada a um aumento da incidência de quedas, a uma diminuição da força musculare a uma deterioração do equilíbrio, a valiada pela oscilação do corpo na postura ereta. Por outro lado, tem sido demonstrado que a suplementação associada de cálcio e vitamina $D$ em idosos deficientes contribui para melhoria destes aspectos da função neuro-muscular. Nesta revisão, serão discutidos os mecanismos conhecidos envolvidos na a ssoc iação entre vitamina D e função neuromuscular, e também a suplementação de vitamina $D$ e cálcio na prevenção de fraturas osteoporótic a snão-vertebrais sob a perspectiva dos efeitos neuro-musc ula res. (Arq Bras Endoc rinol Metab 2005;49/4:495-502)

Descritores: Vitamina D; Quedas; Força muscular, Oscilação postural; Fraturas osteoporótic as não-vertebra is

\begin{abstract}
Role of Vitamin $D$ in the Neuro-Muscular Function.

Through its action in the kidney, intestines, bone and parathyroid glands vitamin $\mathrm{D}$ is a major regulator of calcium homeostasis and for the development of a healthy skeleton. Moreover, receptors for this homone are present in almost all body tissues and other actions which a re not related to the mineral metabolism have been imputed to it. In the skeletal muscle cell, vitamin D acts through the classic mechanism of binding to a nuclear receptor and also by binding to a membrane receptor, camying out actions that involve calcium transport, protein synthesis and kinetics of musc le contraction. C linic ally, vita min D defic iency, which is very common among the elderly, including the ones in our country, has been related to an increase in the incidence of falls, as well as the reduction of muscle strength and deterioration of body sway, evaluated by the oscillation of the body in the erect position. On the other hand, it has been demonstrated that supplementation of calcium associated to vitamin D in deficient elderly contributes to the improvement of these aspects of the neuro-muscular function. In this review, the mechanisms involved in the association between vitamin $D$ and neuro-muscular function will be discussed, as well as the supplementation of vitamin D and calcium to prevent non-vertebral osteoporotic fractures under the perspective of the neuro-musc ular effects. (Arq Bras Endocrinol Metab 2005;49/ 4:495-502)
\end{abstract}

Keywords: Vitamin D; Falls; Muscle strength; Body sway; Non-vertebral fractures revisão

Márcia A. Carneiro Pedrosa
Marise Lazaretti Castro

Disciplina de Endocrinologia da U niversidade Federal de São Paulo, Escola Paulista de M edicina, São Paulo, SP.
R ecebi do em 19/08/04

R evisado em 08/03/05 A ceito em 12/ 05/ 05 
A VITAMINA D ATRAVÉS DE SUAS AÇÕES no intestino, rim, osso e glândulas paratiróides é um hormônio fundamental para a homeostase do cálcio e para o desenvolvimento de um esqueleto saudável. Entretanto, receptores deste hormônio podem ser encontrados em quase todos tecidos do nosso organismo e outras ações não relacionadas ao metabolismo mineral têm sido imputadas a ele. Dentre estes efeitos estão as ações sobre o músculo esquelético envolvendo o transporte de cálcio e a síntese protéica (1-4). Além disto, a deficiência de vitamina $D$ tem sido relacionada à diminuição da força e da massa muscular (5-8), com prejuízo do equilíbrio e aumento da incidência de quedas (9-11). Como a deficiência de vitamina $D$ é considerada um dos principais determinantes da osteoporose senil e tem se mostrado muito mais freqüente do que se imaginava no indivíduo idoso, estes efeitos neuromusculares tornaram-se relevantes na prevenção das fraturas osteoporóticas. N ossa intenção neste trabalho será de apresentar uma revisão de literatura sobre os efeitos neuromusculares da vitamina D.

\section{RSIOLOGIA}

A maior fonte de vitamina $D$ do organismo é sua síntese realizada na pele, catalisada pelas irradiações ultravioletas, sendo que as fontes alimentares contribuem apenas com uma pequena parcela das necessidades diárias. A vitamina $D$ proveniente da síntese em animais é denominada de colecalciferol ou Vitamina $D_{3} \mathrm{e}$ a de origem vegetal é o ergocalciferol ou $\mathrm{V}$ itamina $\mathrm{D}_{2}$. Ambas participam dos mesmos processos biológicos e das mesmas vias de metabolização, com potências biológicas equivalentes.

A partir da exposição aos raios ultravioleta $B$ (UVB), o 7-dehidrocolesterol presente na derme e epiderme é transformado em vitamina $D_{3}$. Esta forma não metabolicamente ativa é transportada pela corrente sanguínea até o fígado, onde sofre uma hidroxilação no carbono 25, tornando-se a 25-hidroxivitamina D [25(OH)D] ou calcidiol. A maioria da 25 $(\mathrm{OH}) \mathrm{D}$ produzida é depositada no tecido gorduroso, seu principal reservatório. A produção da $25(\mathrm{OH}) \mathrm{D}$ no fígado, além de rápida, sofre pouca regulação. D este modo, seus níveis plasmáticos refletem a reserva corporal de vitamina D. Para se tornar ativa, a vitamina $D$ necessita ainda de uma última hidroxilação na posição 1 , que ocorre nas mitocôndrias dos túbulos contornados proximais do rim, sob ação da enzima 1$\alpha$ hidroxilase, transformando-se em 1,25 dihidroxivitamina $\mathrm{D}\left[1,25(\mathrm{OH})_{2} \mathrm{D}\right]$ ou calcitriol. Esta passagem renal, ao contrário da hepática, é estreitamente regulada por vários fatores. A elevação plasmática do PTH e a diminuição do fosfato estimulam a atividade da 1- $\alpha$ hidroxilase. A $1,25(\mathrm{OH})_{2} \mathrm{D}$ retro-regula sua produção, inibindo a atividade da 1- $\alpha$ hidroxilase, 0 mesmo ocorrendo com a redução do PTH e a elevação do fosfato (12). O calcitriol é um hormônio bastante potente que circula em concentrações cerca de 1000 vezes inferiores ao seu precursor, o calcidiol. A figura 1 sumariza a seqüência de eventos envolvidos na síntese da 1,25 dihidroxivitamina $D_{3}$.

\section{Ações da Vitamina D no Músculo Esquelético}

O s primeiros trabalhos sobre as ações da vitamina D no músculo esquelético tratavam do mecanismo intracelular de contração muscular e foram realizados em animais $(1,3,4,13)$. M ais tarde surgiram estudos clínicos demonstrando a presença de uma miopatia em pacientes com osteomalácia por deficiência grave de vitamina D (14). O s efeitos da deficiência ou insuficiência de vitamina $D$ nos parâmetros da função neuro-muscular em idosos têm ganhado cada vez mais atenção dos pesquisadores.

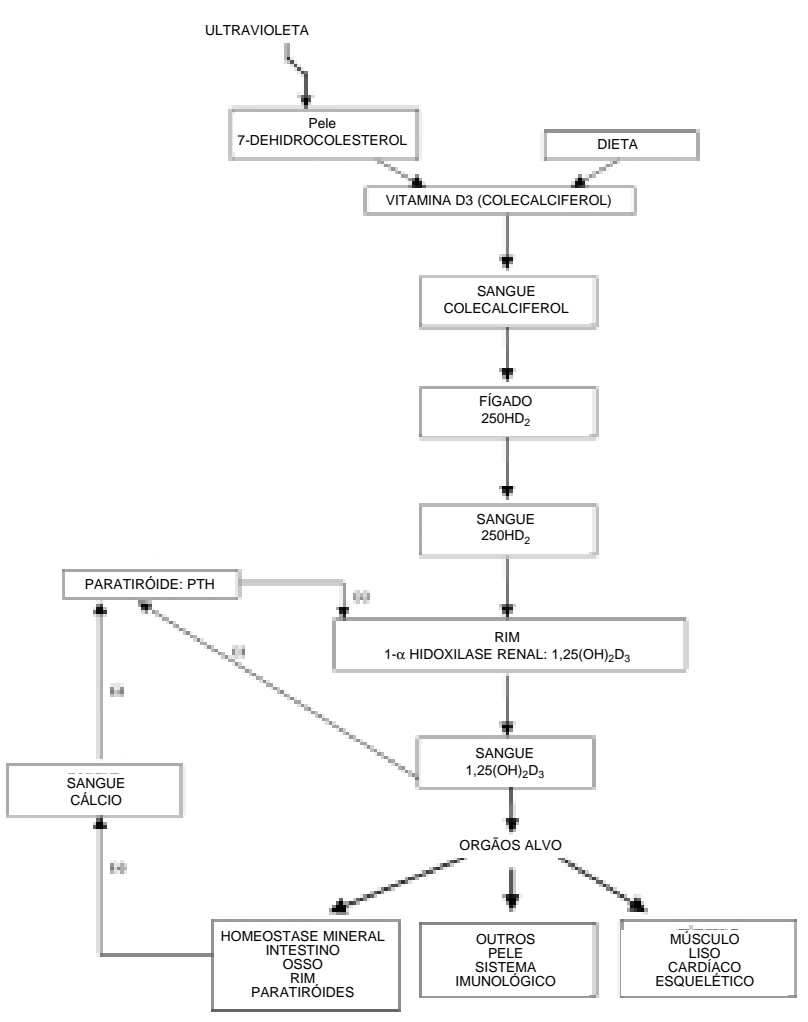

Figura 1. Representação esquemática da seqüência de eventos envolvidos na síntese da $1,25(\mathrm{OH})_{2} \mathrm{D}_{3}$.

Arq Bras Endocrinol Metab vol 49 no 4 Agosto 2005 
U $\mathrm{m}$ dos primeiros aspectos estudados sobre as ações musculares da vitamina $D$ foi sua participação no transporte ativo do cálcio para o interior do retículo sarcoplasmático (RS) de coelhos. $\mathrm{N}$ a presença de deficiência de vitamina $D$, este transporte encontra-se reduzido e se normaliza com o pré-tratamento com vitamina $D$ (1). Bolland e col. (2) sugeriram que a $1,25(\mathrm{OH})_{2} \mathrm{D}$ seria a responsável pela estimulação do transporte ativo de cálcio para o interior do RS pela cálcio-AT Pase e que a atividade desta enzima seria regulada pela fosforilação de proteínas na membrana do RS estimulada pela $1,25(\mathrm{OH})_{2} \mathrm{D}$ (15).

$O$ utros efeitos da vitamina $D$ na célula muscular esquelética relacionam-se ao metabolismo e à síntese protéica. A adição de calcitriol em cultura de tecido de músculo de ratos deficientes aumentou tanto 0 conteúdo intracelular de ATP, quanto à síntese protéica (3), e em músculo de coelhos raquíticos o conteúdo de troponina $C$, uma proteína do complexo actinomiosina com alta afinidade pelo cálcio, encontravase diminuído quando comparado ao músculo de animais normais (4). A função muscular, isto é, a cinética da contração muscular, também foi estudada. Rodman e Baker (13) encontraram prolongamento da fase de relaxamento do músculo de ratos deficientes em vitamina D. Estes achados corroboram os resultados de Curry e col. (1) e de Bolland e col. (2), nos quais a deficiência de vitamina $D$ produziu uma redução do transporte ativo de cálcio para o interior do RS, processo fundamental para o relaxamento muscular.

Em humanos, G lerup e col. (6) encontraram tempo de contração e relaxamento mais lentos em pacientes com miopatia por deficiência de vitamina $D$ do que em controles normais. Estes achados são condizentes com a biópsia muscular de pacientes com osteomalácia que mostra atrofia de fibras musculares do tipo II $(4,13)$, cuja principal característica funcional é a contração rápida. Este mesmo tipo de atrofia muscular foi revertido após 6 meses de tratamento com um análogo sintético da vitamina $D, 01$ alfa-hidroxicolecalciferol, que promoveu aumento tanto no número relativo como na área de secção transversa das fibras do tipo II (14).

A miopatia produzida por deficiência de vitamina D apresenta quadro clínico característico de dor muscular difusa e fraqueza dos músculos proximais, especialmente dos antigravitacionais (extensores, flexores e abdutores do quadril e extensores e flexores do joelho), produzindo dificuldades na marcha e em atividades mais simples como se levantar de uma cadeira $(6,16,17)$.

Em resumo, a vitamina $D$, através de suas ações sobre a regulação do transporte de cálcio $(1,2)$, síntese protéica $(3,4)$ e cinética da contração $(6,14)$, é impor- tante para manutenção da massa, da força e da velocidade de contração do músculo esquelético.

O s efeitos musculares da vitamina $D$ são mediados por via genômica e por via não-genômica. Os efeitos genômicos são os mais estudados e reconhecidos, e seguem o mecanismo dos hormônios esteróides. Consistem na ligação da $1,25(\mathrm{OH})_{2} \mathrm{D}$ a um receptor nuclear específico (VDR), resultando em modificações na transcrição genética do RN A mensageiro e subseqüente síntese protéica de novo $(18,19)$.

A presença de VDR foi demonstrada em células do músculo esquelético por Simpson e col. na década de 1980 (20) e, desde então, vários estudos tentam demonstrar a sua importância para função muscular. Endo e col. (21) encontraram um desenvolvimento muscular anormal em ratos nos quais o gene do VDR fora eliminado (knock-out), caracterizado por fibras musculares menores e por expressão persistentemente elevada de marcadores que deveriam ser encontrados apenas na fase de diferenciação miogênica. $M$ ais recentemente (22), foi encontrado, em biópsias de tecido muscular de mulheres jovens e adultas submetidas à cirurgia ortopédica, que a expressão do VDR diminui com a idade, sugerindo que esta alteração pode contribuir para fraqueza muscular encontrada em idosos com deficiência de vitamina $D(5)$.

Os efeitos musculares não genômicos da vitamina $\mathrm{D}$ são rápidos, não dependentes de síntese protéica, e envolvem a ativação de segundos mensageiros e a fosforilação de proteínas intracelulares. Até recentemente não se conheciam os mediadores deste efeito e se acreditava que estes efeitos não dependiam da ligação com o VDR. Entretanto, um estudo recente (18) demonstrou que 0 tratamento com 1,25 $(\mathrm{OH})_{2} \mathrm{D}_{3}$ induziu a translocação do VDR para fração membrana plasmática dos mioblastos, sugerindo que 0 VDR deva ser também o responsável pelos efeitos nãogenômicos da $1,25(\mathrm{OH})_{2} \mathrm{D}_{3}$.

\section{Envelhecimento e deficiência de vitamina D}

O s principais indicadores das reservas corporais de vitamina D são os níveis plasmáticos de $25(\mathrm{OH}) \mathrm{D}$, entretanto, as concentrações plasmáticas ideais deste hormônio para a manutenção das funções fisiológicas normais ainda são motivo de discussão na literatura. A classificação desenvolvida por McKenna \& Freaney (23) tem sido mais amplamente utilizada e se encontra na tabela 1.

A hipovitaminose $D$ caracteriza-se por níveis séricos de $250 \mathrm{HD}$ abaixo do limiar considerado suficiente para manutenção de uma secreção normal de PTH pelas paratiróides. Isto se aplica especialmente 
Tabela 1. Definição da reserva corporal de vita mina $D$ baseada nos níveis séricos de 25OHD*.

\begin{tabular}{lcc}
\hline \multirow{2}{*}{ Condição } & \multicolumn{2}{c}{ Níveis séricos de 250HD } \\
\cline { 2 - 3 } & $\mathrm{nmol} / \mathrm{L}$ & $(\mathrm{ng} / \mathrm{ml})$ \\
\hline Desejá veis & $>100$ & $>40$ \\
Hipovitaminose D & $<100$ & $<40$ \\
Insuficiência de vitamina D & $<50$ & $<20$ \\
Defic iência de vitamina D & $<25$ & $<10$ \\
\hline
\end{tabular}

*Adaptada de McKenna \& Freaney (23)

para o idoso, que parece necessitar de concentrações de $250 \mathrm{HD}$ mais elevadas para manter níveis normais de PTH . Na insuficiência já se evidencia elevação nas concentrações de PTH circulantes, traduzindo um hiperparatiroidismo secundário, redução das concentrações de $1,25(\mathrm{OH})_{2} \mathrm{D}$, assim como um maior risco de fraturas. $\mathrm{N}$ a deficiência de vitamina $\mathrm{D}$ já se evidenciam as alterações histológicas clássicas da osteomalácia e raquitismo, com deficiente mineralização da matriz osteóide, além de aumento acentuados dos níveis de PTH . N esta situação, a hipocalcemia e hipofosfatemia podem ser manifestas.

Entretanto, vale ressaltar que existem outras classificações na literatura, e que a correlação entre as concentrações plasmáticas e as correspondentes manifestações clínicas ainda permanecem em discussão. A ausência de uma padronização entre os vários métodos existentes para dosagem de $250 \mathrm{H}$ D é uma das responsáveis por esta controvérsia sobre os valores da normalidade (24). De qualquer forma, é consenso que os valores atualmente aceitos como normais estejam muito acima do que se considerava anteriormente, quando se pretendia apenas evitar a osteomalácia clássica. 0 que se verifica na realidade é que existe em amplo espectro de manifestações clínicas e laboratoriais até que se atinjam valores extremos que caracterizam a osteomalácia. As dosagens cada vez mais freqüentes de $250 \mathrm{HD}$ em diferentes populações têm demonstrado que a presença de valores anormais é muito mais freqüente do que se imaginava, especialmente em países considerados com graus de insolação suficiente.

Entre os idosos institucionalizados ou residentes na comunidade é bastante freqüente a deficiência de vitamina $D(9,25)$, inclusive em nosso meio. Os resultados preliminares de uma pesquisa que está sendo realizada por nosso grupo em idosos da cidade de São Paulo, SP demonstraram elevada prevalência de deficiência de vitamina D, estando presente em $54 \%$ dos idosos institucionalizados e em $35,5 \%$ dos idosos ambulatoriais (26).
Dentre os fatores de risco para a hipovitaminose $D$ nesta população podemos destacar a dieta pobre em vitamina D, a baixa exposição solar, a diminuição da eficiência da síntese cutânea, assim como da absorção intestinal, e a redução da atividade da $1 \alpha$-hidroxilase renal, que acompanham o enveIhecimento, além de terapia com anticonvulsivantes e/ ou outras drogas que interfiram no metabolismo da vitamina $D$ (27). Paralelamente à deficiência de vitamina $D$, os idosos apresentam freqüentemente uma diminuição da massa muscular, causada por redução tanto no tamanho como no número de fibras musculares, sendo que as fibras do tipo II (contração rápida) são mais afetadas que as fibras do tipo I (contração lenta) (28). Associada a esta perda ocorre também diminuição da força muscular, ambas repercutindo negativamente no desempenho funcional e aumentando o risco de quedas e fraturas nesta população.

Existem evidências de que a presença de baixos níveis plasmáticos de vitamina $D$ estaria envolvida na fraqueza muscular associada ao envelhecimento. Em um estudo transversal em pacientes ambulatoriais com mais de 65 anos de idade, realizado na Suiça, Bischoff e col. (5) encontraram uma correlação positiva entre a força muscular avaliada pela potência dos músculos extensores do joelho (LEP) e os níveis de 1,25dihidroxivitamina $D$ em homens e mulheres. Após ajustamento para idade, a LEP foi menor nos indivíduos com deficiência de vitamina D $(250 \mathrm{HD}<$ $30 \mathrm{nmol} / \mathrm{L}$ ). Em mulheres árabes que usavam burca e com deficiência de vitamina $D(250 \mathrm{HD}<20 \mathrm{nmol} / \mathrm{L})$, G lerup e col. (6) encontraram correlação positiva entre a força muscular isométrica dos músculos extensores do joelho e os níveis plasmáticos de 25(OH )D. Após 3 meses de tratamento com injeções intramusculares de 100.000U I de ergocalciferol por mês e de uma suplementação oral diária com 1200mg de cálcio e 400 I de ergocalciferol, obteve-se aumento significativo da força muscular, que foi ainda maior após 6 meses de tratamento.

Arq Bras Endocrinol Metab vol 49 no 4 Agosto 2005 
Verhaar e col. (7) investigaram a influência da vitamina $D$ sobre a força muscular em mulheres holandesas com mais de 70 anos. Após 6 meses de suplementação com $0,5 \mu \mathrm{g}$ de alfacalcidiol, observou-se um aumento significativo da força isométrica dos músculos do joelho quando comparado aos valores basais nas mulheres com deficiência $(250 \mathrm{HD}<20 \mathrm{nmol} / \mathrm{L})$. Em outro estudo, também realizado em mulheres holandesas com mais de 65 anos, participantes do Estudo L ongitudinal do Envelhecimento de Amsterdã (LASA) (8), a presença de baixos níveis séricos de vitamina $D$ e de níveis séricos elevados de PTH foi associada a um aumento do risco de sarcopenia, definida como perda de força muscular superior a $40 \%$ e perda de massa muscular superior a 3\% em 3 anos de seguimento.

No entanto, nem todos os estudos observaram associação entre vitamina $D$ e força muscular. Boonen e col. (29), em um estudo transversal com mulheres belgas saudáveis (idade média 75,4 anos), não encontraram correlação entre a força dos músculos extensores do joelho e os níveis plasmáticos de $1,25(\mathrm{OH})_{2} \mathrm{D}$, embora tanto a força muscular como os níveis plasmáticos de $1,25(\mathrm{OH})_{2} \mathrm{D}$ tenham declinado em função da idade. Resultados semelhantes foram obtidos por Verreault e col. (30) que, através de um estudo longitudinal, não encontraram associação entre os níveis plasmáticos de 25(OH ) D e força muscular.

\section{Vitamina De incidência de quedas}

$\mathrm{N}$ as pessoas idosas, o processo dinâmico de conservação do equilíbrio encontra-se diminuído, fato que se torna evidente pela elevada incidência de quedas (31). Cerca de $87,7 \%$ das fraturas de fêmur encontradas em pacientes de dois hospitais da cidade de São Paulo foram causadas por quedas. D os indivíduos acometidos por estas fraturas, $15 \%$ irão a óbito por complicações como embolismo pulmonar e pneumonia, e $35 \%$ tornar-se-ão dependentes de outras pessoas ou de meios auxiliares para realizarem suas atividades de vida diária (32).

Entre os fatores fisiológicos predisponentes de quedas, podemos destacar como mais importantes a diminuição da força muscular e da sensibilidade proprioceptiva de membros inferiores (M MII) e o aumento da oscilação postural, isto é, da oscilação do corpo quando este se encontra na postura ereta e parada. No que se refere à oscilação postural, o aumento da instabilidade lateral (ou da oscilação no plano frontal) tem sido considerada uma das principais alterações do equilíbrio decorrentes do envelhecimento, de modo que sua mensuração é imprescindível para avaliar 0 risco futuro de quedas (31). A medida da oscilação postural é realizada através de um equipamento que permite quantificar o deslocamento do corpo ao nível da cintura nos planos frontal e sagital, enquanto 0 indivíduo é instruído a permanecer em pé, com os braços ao lado do corpo e os pés juntos, o mais estável possível, por um período de 30 segundos, enquanto fixa um alvo à altura dos olhos (33).

Vários investigadores pesquisaram a participação da deficiência de vitamina $D$ no aumento da oscilação postural e da incidência de quedas entre idosos $(3,9-11,35)$. Em um estudo realizado com 83 idosos institucionalizados australianos, observou-se que aqueles que já haviam sofrido alguma queda apresentavam níveis plasmáticos mais baixos de $25(\mathrm{OH}) \mathrm{D}$ e mais elevados de PTH do que os que nunca haviam caído (9). A correlação entre vitamina $D$, oscilação postural e ocorrência de quedas também foi investigada em uma população de 237 mulheres alemãs pósmenopausadas com osteoporose $(63(7,4)$ anos). Os níveis plasmáticos de 250 H D correlacionaram-se negativamente com a oscilação postural e com o número de quedas, enquanto que a oscilação postural correlacionou-se positivamente com o número de quedas e com a ocorrência de fraturas nas costelas (11).

Em outra pesquisa realizada com mulheres residentes nas cidades de Bad Pyrmont e $\mathrm{H}$ ameln na Alemanha, a terapia de curta duração com cálcio e vitamina $D$ reduziu o número de quedas e permitiu uma melhoria do equilíbrio corporal, representada pela diminuição da oscilação postural (10). Foram randomizadas 148 mulheres, com idade superior a 70 anos e com deficiência de vitamina $D(25(\mathrm{OH}) \mathrm{D}=$ $23 \mathrm{nmol} / \mathrm{L}$ ). As mulheres receberam $1200 \mathrm{mg}$ de cálcio elementar isolado ou associado a $800 \mathrm{U}$ I de colecalciferol diariamente por 8 semanas. Comparado à monoterapia com cálcio, a suplementação com cál cio e vitamina $D$ resultou em uma diminuição no PTH plasmático de $18 \%$ e em uma redução da oscilação postural no diâmetro sagital de $9 \%$ Dentre as participantes do estudo, 137 mulheres foram acompanhadas prospectivamente por 1 ano, e o número de quedas observadas no grupo que só recebeu cálcio foi maior do que no grupo que recebeu cálcio e vitamina $D$. R esultados semelhantes foram obtidos por Bischoff e col. (34) em mulheres suíças institucionalizadas, com mais de 60 anos e com deficiência de vitamina D. Estes autores demonstraram que a suplementação com $1200 \mathrm{mg}$ de cálcio elementar e $800 \mathrm{U}$ I de colecalciferol reduziu o número de quedas por pessoa em $49 \%$ e melhorou a função músculo-esquelética, após 3 meses de tratamento. N esta mesma população suíça, estudo mais recente realizado em mulheres e homens com mais de 
70 anos mostrou que a suplementação diária de $1 \mu \mathrm{g}$ de alfacalcidiol durante 9 meses foi associada a um menor número de indivíduos que caíam, no entanto, esta associação só foi observada naqueles participantes cuja ingestão diária de cálcio era superior a $512 \mathrm{mg} / \mathrm{dia}$ (35). Em mulheres norte-americanas pós-menopausadas não deficientes em vitamina $D(25(\mathrm{OH}) \mathrm{D}=$ $80 \mathrm{nmol} / \mathrm{L}$ ), a suplementação com calcitriol promoveu um declínio da incidência de quedas em 38\%, bem como mostrou uma forte tendência para reduzir 0 número de fraturas relacionadas a quedas (36).

R evisão sistemática publicada recentemente (37), incluindo 5 estudos prospectivos, duplo-cego, randomizados e controlados, sugere que a vitamina $D$ pode reduzir o risco de uma pessoa idosa cair em $22 \%$ sendo este beneficio mais bem estabelecido para mulheres do que para os homens. Além disso, foi sugerido que seria necessário tratar 15 pessoas com vitamina $D$ para prevenir uma pessoa de cair. A importância de se combinar o cálcio à suplementação de vitamina $D$ não ficou bem esclarecida, embora os autores acreditem que o cálcio não foi responsável por mediar significativamente 0 efeito da vitamina $D$ após meta-análise. A tabela 2 abaixo apresenta um resumo dos principais estudos clínicos sobre os efeitos da suplementação de vitamina $D$ sobre a função neuro-muscular e sobre a incidência de quedas.

\section{Papel do hipenparatiroidismo sec undánio}

O aumento do PTH mostrou-se um preditor de quedas independente da vitamina $D$ em estudo realizado por Stein e col. (9). 0 mesmo foi observado em trabalho mais recente, também realizado por um grupo australiano (38), em que os níveis de PTH e de $250 \mathrm{H}$ D foram preditores significantes para primeira queda, porém após ajustes para idade, incontinência e severidade da doença, apenas os níveis de PTH permaneceram como preditores significantes. Em células musculares de ratos, o tratamento com PTH reduziu o conteúdo de fosfato inorgânico e da cálcio-ATPpase (39), alterações estas que também ocorrem em culturas de células de animais deficientes em vitamina $D$. Em estudos clínicos, pacientes com hiperparatiroidismo primário apresentavam fadiga e fraqueza muscular que tiveram melhora importante após paratiroidecetomia bem sucedida (40). N a miopatia associada à osteomalácia, coexistem deficiência de vitamina $D$ e aumento dos níveis plasmáticos de PTH $(16,17)$. Por outro lado, um aumento na ingestão, ou mesmo a suplementação oral de cálcio podem suprimir a secreção de PTH (17) e minimizar os efeitos do hiperparatiroidismo secundário. Todos estes dados sugerem que os efeitos musculares da vitamina $D$ estão de alguma maneira associados ao PTH e provavelmente ao metabo-

Tabela 2. Efeitos da suplementação de vitamina D sobre a função neuro-musculare sobre a incidência de quedas.

\begin{tabular}{|c|c|c|c|c|c|c|}
\hline Estudo & Tratamento & $\begin{array}{l}\text { Peńodo } \\
\text { de obser- } \\
\text { vação } \\
\text { meses }\end{array}$ & Indivíduos & $\begin{array}{l}\text { Níveis séricos } \\
\text { iniciais de } \\
250 \mathrm{HD} \\
\text { (nmol/L) } \\
\text { média (DP) }\end{array}$ & $\begin{array}{c}\text { Idade } \\
\text { (anos) } \\
\text { Média (DP) }\end{array}$ & Efeitos \\
\hline $\begin{array}{l}\text { Pfeifere } \\
\text { col. (10) }\end{array}$ & $\begin{array}{c}\text { 800Ul Colecalciferol } \\
+1200 m g \\
\text { cálcio/dia Vo }\end{array}$ & 2 & $\begin{array}{c}148 \text { mulheres a mbu- } \\
\text { latoria is }\end{array}$ & $25,7(13,6)$ & $74,0(1,0)$ & $\begin{array}{c}\text { Diminuição signific ativa } \\
\text { da osc ilação postural e } \\
\text { do no de quedas após } 1 \\
\text { ano de seguimento }\end{array}$ \\
\hline $\begin{array}{l}\text { Glerup e } \\
\text { col. (6) }\end{array}$ & $\begin{array}{c}\text { 100.000Ul Ergocalci- } \\
\text { ferol IM/mês + 400Ul } \\
\text { Ergocalciferol + } \\
\text { 1200mg cálcio/dia } \\
\text { VO }\end{array}$ & 6 & $\begin{array}{l}55 \text { mulheres ambu- } \\
\text { latoria is (c/ burca) }\end{array}$ & $6,7(0,6)$ & $32,2(1,4)$ & $\begin{array}{l}\text { Melhora signific ativa da } \\
\text { força dos músculos } \\
\text { extensores do joelho }\end{array}$ \\
\hline $\begin{array}{l}\text { Bischoff e } \\
\text { col. (34) }\end{array}$ & $\begin{array}{c}\text { 800Ul Colecalciferol } \\
+1200 \mathrm{mg} \\
\text { cálcio/dia Vo }\end{array}$ & 3 & $\begin{array}{l}122 \text { mulheres institu- } \\
\text { cionalizadas }\end{array}$ & $41,0(25,5)$ & $85,0(6,0)$ & $\begin{array}{c}\text { Diminuição } 49 \% \text { do } \\
\text { número de quedas por } \\
\text { pessoa e melhora signi- } \\
\text { fic ativa da função neuro } \\
\text { muscular }\end{array}$ \\
\hline $\begin{array}{l}\text { Dukase } \\
\text { col. (35) }\end{array}$ & $\begin{array}{c}1 \mu \mathrm{g} \text { alfacalcidiol/ } \\
\text { dia VO }\end{array}$ & 9 & $\begin{array}{l}191 \text { homense } 187 \\
\text { mulheres a mbulato- } \\
\text { ria is }\end{array}$ & $74,8(11,6)$ & $\geq 70$ & $\begin{array}{c}\text { Diminuição significativa } \\
\text { do número de indivíduos } \\
\text { que caíam }\end{array}$ \\
\hline $\begin{array}{l}\text { Gallagher } \\
\text { (36) }\end{array}$ & $\begin{array}{c}0,25 \mu \mathrm{g} \text { calcitriol/ } 2 \\
\text { vezes dia VO }\end{array}$ & 36 & $\begin{array}{c}489 \text { mulheres a mbu- } \\
\text { latoria is }\end{array}$ & 80 & $73,5(2,1)$ & $\begin{array}{l}\text { Diminuição } 38 \% \text { do } \\
\text { número de quedas por } \\
\text { pessoa }\end{array}$ \\
\hline
\end{tabular}


lismo do cálcio. Porém, é difícil definir o papel isolado de cada um, devido à interdependência entre baixos de níveis de cálcio e de vitamina $\mathrm{D}$ e a presença de hiperparatiroidismo secundário.

\section{CONCLUSÕES}

$H$ á várias evidências de que a vitamina $D$ participa de dois aspectos importantes da função neuro-muscular: a força muscular e o equilíbrio. Especialmente no que se refere à célula muscular esquelética, sabe-se que a vitamina $D$ atua através de um receptor específico, exercendo ações que envolvem desde a síntese protéica até a cinética de contração muscular, que repercutem na capacidade de realizar movimentos rápidos que evitam uma queda. No entanto, ainda há muito a ser descoberto sobre o papel específico da vitamina $D$ sobre o sistema nervoso central. Pesquisas futuras são necessárias para ratificar os benefícios da suplementação oral de vitamina $D$ sobre a força muscular, oscilação postural e incidência de quedas, tão comuns entre os idosos. Se obtidos resultados positivos, estes poderão nortear a implementação de políticas de saúde para a população geriátrica brasileira, oferecendo uma alternativa barata e eficiente para prevenção das fraturas osteoporóticas.

\section{REFERÊNCIAS}

1. Cumy OB, Basten J F, Franc is MJ, Smith R. Calcium uptake by sarcoplasmatic reticulum of muscle from vitamin $D$ defic ient rabbits. Nature 1974;249:83-4.

2. Bolland R, de Boland AR, Ritz E, Hasselbach W. Effect of 1,25 -dihydroxicholecalciferol on sarcoplasmatic reticulum calcium transport in strontium fed rats. Calcif Tissue Int 1983;35:190.

3. Birge SJ, Haddad J G. 25-Hydroxyc holec a lc iferol stimulation of musc le metabolism. J Clin Invest 1975;56:1100-7.

4. Pointon JJ, Francis MJ, Smith R. Effect of vitamin D deficiency on sarcoplasmatic reticulum function and troponin C concentration of rabbit skeletal musc le. Clin Sci 1979;57:257-63.

5. Bischoff HA, Stahelin HB, Niklaus U, Ehsrsam R, Vonthein $R$, Perig-Chiello $P$, et al. Musc le strength in the elderly: its relation to vitamin D metabolites. Arch Phys Med Rehabil 1999;80:54-8.

6. Glenup $H$, Mikkelsen $K$, Poulsen L Hypovitaminosis $D$ myopathy without biochemical signs of osteomalacic bone involvement. Calcif Tissue Intem 2000;66:419-24.

7. Verhaar HJ, Samson MM, Jansen PA, de Vreede PL, Manten JW, Duursma SA. Muscle strength, functional mobility and vitamin $D$ in older women. Aging 2000;12:455-60.
8. Vissser $M$, Deeg DJ H, Lips P. Low vitamin D and high parathyroid homone levels as deteminants of loss of muscle strength and muscle mass (sarcopenia): The Longitudinal Aging Study Amsterdam. J Clin Endocrinol Metab 2003;88:5766-72.

9. Stein MS, Wark JD, Scherer SC, Med DG, Walton SL, Chick $P$, et al. Falls relate to vitamin $D$ and parathyroid homone in an Australian nursing home and hostel. J Am Geniatr Soc 1999;47:1195-201.

10. Pfeifer M, Begerow B, Minne $H$, Abrams C, Nachtigall D, Hansen C. Effects of a short-tem supplementation on body sway and secondary hyperparathyroidism in eld enly women. J Bone Miner Res 2000;15:1113-8.

11. Pfeifer $M$, Begerow $B$, Minne $H$, Schlotthauer $T$, Pospeschill M, Scholz M, et al. Vitamin D status, trunk muscle strength, body sway, falls, and factures among 237 postmenopausal women with osteoporosis. Exp Clin Endocrinol Diabetes 2001;109:87-92.

12. Bianco AC, Lazaretti-Castro M. Fisiologia do metabolismo osteomineral. In: Aires MM, editor. Fisiologia. 3 a edição. Rio de Janeiro: Guanabara Koogan; 1999. p. 870-4.

13. Rodman J S, Baker T. Changes in the kinetics of muscle contraction in vitamin D depleted rats. Kidney Int 1978;13:189-93.

14. Sorensen $\mathrm{OH}$, Lund $\mathrm{B}$, Saltin $\mathrm{B}$, Andersen RB, Hjorth L, Melsen $F$, et al. Myopathy in bone loss of ageing: improvement by treatment with 1 alpha-hydrxycholecalciferol and calcium. Clin Sci 1979;56:157-61.

15. Bolland R. Role of vitamin D in skeletal muscle function. Endocr Rev 1986;7:434-48.

16. Zambras K, Dagogo-Jack S. Reversible muscle weakness in patients with vitamin D deficiency. West J Med 1997;167:435-9.

17. Ronin DI, Yeongchi W, Vinod S, MacLean IC. Intractable muscle pain syndrome, osteomalacia, and axonopathy in long tem use of Phenytoin. Arch Phys Med Rehabil 1991;72:755-8.

18. Capiati D, Benassati S, Bolland RL. 1,25(OH)-vitamin $D_{3}$ induces transloc ation of the vita min $\mathrm{D}$ receptor (VDR) to the plasma membrane in skeletal muscle cells. J Cell Biochem 2002;86:128-35.

19. Noman AW, Nemere I, Zhou LX, Bishop J E, Lowe KE, Maiyar AC. $1,25(\mathrm{OH})_{2}$-vitamin $D_{3}$, a steroid homone that produces biologic effects via both genomic and nongenomic pathways. J Steroid Biochem Mol Biol 1992;41:231-40.

20. Simpson RU ThomasGA, Amold AJ . Identific ation of 1,25dihydroxyvita min $D_{3}$ receptors and activities in musc le. J Biol Chem 1985;260:8882-91.

21. Endo I, Inoue D, Mitsui T, Umaki Y, Aka ike M, Yoshizawa T, et al. Deletion of vitamin $D$ receptorgene in mice results in abnormal skeletal muscle development with deregulated expression of myoregulatory transcription factors. Endocrinology 2003;144:5138-44.

22. Bischoff-Ferrari, Borchers M, Gudat F, Stähelin HB, Dick $W$. Vitamin $D$ receptor exp ression in human musc le tissue decreases with age. J Bone Miner Res 2004;19:265-9.

23. Mckenna MJ, Freaney R. Secondary hyperparathyrodism in the elderly: means to defining hypovitaminosis D. Osteoporos Int 1998;Sup pl. 8:S3-S6. 
24. Lips $P$. Which circulating level of 25-hydroxyvitamin $D$ is appropriate. J Steroid Biochem Mol Biol 2004;89-90:611-4.

25. Chapuy MC, Schott AM, Gamero P, Hans D, Delmas PD, Meunier PJ. Healthy elderly French women living at home have secondary hyperparathyroidism and high bone tumover in winter. J Clin Endocrinol Metab 1996;81:1129-33.

26. Saraiva GL, Cendoroglo MS, Ramos LR, Quinino LM, Kunii I, Quinino $M L$, et al. High prevalence of vitamin D deficiency and hyperparathyroidism in an elderly population in the city of São Paulo, Brazil. Osteoporos Int 2000;15(Supl 1):P225MO.

27. Holick MF, Matsuoka LY, Wortsman J. Age, vita min D and so lar ultra violet radiation. Lancet 1989;1:1104-5.

28. Lexell J. Human aging, muscle mass, and fibertype composition. J Gerontol A Biol Sci Med Sci 1995;50A:11-6.

29. Boonen S, Lysens R, Verbeke G, J oosten E, Dejaeger E, Pelemans W, et al. Relationship between age-associated endocrine deficiences and muscle function in elderly women: a cross-sectional study. Age and Ageing 1998;27:449-54.

30. Verreault R, Semba RD, Volpato S, Femuci L, Fried $L P$, Guralnick J A. Low serum vita min D does not predict new disability or loss of musc le strength in older women. J Am Geriatr Soc 2002;50:912-7.

31. Lord SR, Rogers MW, Howland A, Fitzpatrick R. Lateral stability, sensorimotor function and falls in older people. J Am Geriatr Soc 1999;47:1077-81.

32. Ramalho AC, Laza retti-Castro M, Hauache O, Vieira J G, Takata E, Cafalli F, et al. Osteoporotic fractures of proximal femur: clinical and epidemiological features in a population of the of São Paulo. São Paulo Med J 2001;119:48-53.

33. Lord SR, Ward J A, Williams P, Anstey K. Physiologic al factors associated with falls on older community-dwelling women. J Am Geriatr Soc 1994;42:1110-7.
34. Bischoff HA, Stä helin HB, Dick W, et al. Effects of vita min $D$ and calcium supplementation on falls: $A$ randomized c ontrolled trial. J Bone Miner Res 2003;18:343-51.

35. Dukas L, Bischoff HA, Lind pa intner LS, Schacht E, BirknerBinder D, Damm TN, et al. Alfacalcidiol reduces the number of fallers in a community-dwelling elderly population with a minimum calcium intake of more than 500 Mg daily. J Am Geriatr Soc 2004;52:230-6.

36. Gallagher JC. The effects of calcitriol on falls and fractures and physic al performance tests. J Steroid Biochem Mol Biol 2004;89-90:497-501.

37. Bischoff-Ferrari HA, Dawson-Hughes B, Willet WC, Stähelin HB, Bazemore MG, Zee RY, et al. Effect of vita min D on falls: a Meta-analysis. JAMA 2004;291:1999-2006.

38. Sambrook PN, Chen JS, March LM, Cameron ID, Cumming RG, Lord SR. Serum parathyroid homone predicts time to fall independent of vitamin D status in a frail elderly population. J Clin Endocrinol Metab 2004;89:1572-6.

39. Baczynski R, Massry SG, Magott M, El-Belbessi S, Kohan R, Braulbar N. Effect of parathyroid homone on energy meta bolism of skeletal musc le. Kidney Int 1985;28:722-7.

40. Colliander EB, Strigard K, Westblad P, Rolf C, Nodenstroem J. Muscle strength and endurance after surgery for primary hyperparathyroidism. Eur J Surg 1998;164:489-94.

\section{Endereço para comespondência:}

Marise Laza retti Castro

Caixa Postal 20266

Vila Clementino

04034-970 São Paulo, SP

Fax: (11) 5579-6636

E-mail: mlaza retti@endocrino.epm.br 